\title{
Lamellar assembly and orientation-induced internal micro-voids by cross-sectional dissection of poly(ethylene oxide)/poly(L-lactic acid) blend
}

\author{
Y. T. Hsieh, E. M. Woo* \\ Department of Chemical Engineering, National Cheng Kung University, 701 Tainan, Taiwan
}

Received 3 November 2012; accepted in revised form 13 January 2013

\begin{abstract}
Micro-lamellar patterns and orientation-induced micro-voids (cracks) in spherulites are probed in step-crystallized blends of two crystalline polymers: poly(ethylene oxide) (PEO) and low-molecular-weight poly(L-lactic acid) (PLLA) in different weight fractions, using polarizing light optical microscopy (POM), and scanning electron microscopy (SEM) with water-etching technique. It is revealed that blend composition led to entirely different PLLA lamellar regularities and void patterns. Water-etching into interiors of PEO/PLLA blends show 3D assembly of PLLA lamellae patterns. It is an important datum for structure modeling of banded polymer spherulites in bulk state. The mechanisms for the void/crack patterns and lamellar orientation are exemplified via dissecting into interior spherulites of bulk-form samples.
\end{abstract}

Keywords: biodegradable polymers, biocompatible polymers, PLLA, bulk

\section{Introduction}

Biodegradable polymer materials have attracted great scientific and technological interest at many application areas, such as packaging, biomedical material $[1,2]$. For the packaging and medical applications, poly(lactic acid) (PLA) has one of the highest potentials among biopolyesters [1]. To tailor its crystallization behavior, degradation rate and other material properties for the applications, blending PLA with other biocompatible polymers is a practical and economical approach. PLA also is the one of the interesting polyesters in issues of chiral effect, crack and ring patterns, and spherulitic morphology in polymer physical research [3-7].

Rings and cracks in some semicrystalline polymers have been reported during cooling, crystallization or in contacting with solvents [4-10]. Overall, the conventionally known fact of thermal shrinkage/ contraction upon cooling in different directions accounts only partially for the cracks. Updated studies have pointed out for biodegradable polyesters that cracks and ring bands can be inter-related and interrelations between rings and cracks can be more clearly resolved if interiors of the banding/cracking polymers can be exposed for examination.

Poly(ethylene oxide) (PEO), a water soluble polyether, possesses good biocompatibility and has very low toxicity in bio-medical applications [11, 12]. Phase behavior and biocompatibility of blends of PEO/poly(L-lactic acid) (PLLA) has been studied [13-15], and partial miscibility with phase domains in blends of PEO with PLLA of high molecular weights has been claimed. However, PEO also has been proven to be miscible with low-molecularweight PLLA in our previous work [16]. An early pioneering work by Lustiger et al. [17] dealt with interior morphology correlating with surface ring bands in polyethylene (PE) bulk samples. In that

\footnotetext{
${ }^{*}$ Corresponding author, e-mail: emwoo@mail.ncku.edu.tw (C) BME-PT
} 
work, the fracture surface as examined by SEM was exposed to reveal a central hole (on nuclei center) in banding PE spherulites. However, the interior morphology for general lamellar textures is not clear enough, as comparison to much better resolved top-surface rings and their lamellae patterns. Analyses of bulk PE were thus mainly based on the top-surface morphology, leaving issues of the interior lamellar assembly in banding spherulites still unresolved. This work, using $\mathrm{PEO} / \mathrm{PLLA}$ blend as a model, intended to probe further, focusing on interior lamellae assembly in correlation with surface/interior cracking and banding by taking advantage of the water-soluble property of PEO under water-etching treatment. Such 3D dissection approach was also successfully adapted to interpret the correlation between the inner lamellar assembly, outer surface banding and 3D banding spheroids in poly(ethylene adipate) crystallized at $T_{\mathrm{c}}=28 \pm 11^{\circ} \mathrm{C}[18]$.

Objectives in this letter were to utilize a technique of selectively removing the PEO component for exposing the cross-sectional surfaces of bulk-form samples for dissecting the inner PLLA lamellae to probe the correlations between inner cracks and outer ring bands in PEO/PLLA blend's crystal phases. Lamellar patterns and ring-band types in blends were found to vary with respect to blend compositions. The PEO component, used for helping to induce rings and suppressing cracks, could be easily etched out using pure water after its co-crystallization with PLLA in blends. As PEO and PLLA co-crystallized in two stage-crystallization, the role of PEO in the crystallized PEO/PLLA blend can be regarded as a temporary moldable filler among the PLLA lamellae. In continuing the previous study [16], correlations between the rings, cracks and lamellar pattern in ring-banded spherulites in PEO/PLLA blends were probed in greater details by comparing the lamellae and crack behavior of PLLA crystallizing with different PEO contents in blends. This study mainly focused on the PEO-rich blend compositions, and within this composition range, the blends were known to show unusual radial and irregular crack patterns instead of concentric cracks [16]. Objectives were further probing the mechanisms of lamellar patterns and orientation in ring bands responsible for inducing special types of surface rings and interior lamellar assembly and cracks in crystallized and cooled polymers at micro-scale, by delicately removing PEO from crystallized PEO/ PLLA blends, but without altering the already fixed PLLA crystals, to expose more details of interior morphology.

\section{Experimental \\ 2.1. Materials}

PEO with $M_{\mathrm{w}}=20000 \mathrm{~g} / \mathrm{mol}$, PDI $=1.16, T_{\mathrm{g}}=$ $-60^{\circ} \mathrm{C}$ and $T_{\mathrm{m}}=64^{\circ} \mathrm{C}$, was obtained from Aldrich (USA). PLLA was purchased from Polysciences, Inc. (USA), with $M_{\mathrm{w}}=11000 \mathrm{~g} / \mathrm{mol}$, PDI $=1.11$, $T_{\mathrm{g}}=45.3^{\circ} \mathrm{C}$ and $T_{\mathrm{m}}=155^{\circ} \mathrm{C}$. Materials were used as received without further purification.

\subsection{Preparation of PEO/PLLA thin films}

Blends sample films of PLLA with PEO were prepared by solution-casting using chloroform as solvent. Two polymers of intended compositions were dissolved in solvent with a concentration of $4 \mathrm{wt} \%$, well stirred, and cast onto micro glass slides at $45^{\circ} \mathrm{C}$. The solvent in blend films was first evaporated and dried at $45^{\circ} \mathrm{C}$ for $24 \mathrm{~h}$, and then further dried in vacuum at $\sim 40^{\circ} \mathrm{C}$ for several days.

Blend samples were pressed as thin films between two micro glass slides to obtain uniform film thickness $(\sim 10 \mu \mathrm{m})$ on a heating stage. Crystallization of blend samples was done at isothermal $110^{\circ} \mathrm{C}$ (crystallization temperature, $T_{\mathrm{c}}$ ) by quenching from the molten state at maximum melting temperature $\left(T_{\max }\right)=190^{\circ} \mathrm{C}$. Degradation of neat PLLA under static air was analyzed using thermogravimetric analysis (TGA). In air, degradation of neat PLLA initiated at $\sim 200^{\circ} \mathrm{C}$. As a result, $190^{\circ} \mathrm{C}$ was used as $T_{\max }$ in this study. As PEO in blends is easily water soluble, PEO could be water-etched from $\mathrm{PEO} /$ PLLA blends, leaving the PLLA lamellae unaltered by dripping deionized water on to tilted sample. For this purpose, an easily releasable polyimide (PI) film was used for temporary covering the samples during crystallization; after crystallization and cooling, PI film was peeled off from blend samples. Furthermore, a gentle etching process was conducted to maintain the polymer film sticking on the substrate rather than floating on water.

\subsection{Sample characterization}

A polarizing optical microscope (Optiphot-2-POL, Nikon, Japan), equipped with a digital camera charge-coupled device (CCD) and a microscopic hot stage (Linkam THMS-600 with TP-92 tempera- 
ture programmer), was used for characterizing crystalline morphology of the polymers.

Samples of solution-cast films of PEO/PLLA blends were also examined using a scanning electron microscope (SEM) (Quanta-400F, FEI, USA), and its accelerating voltage was $10 \mathrm{kV}$ for revealing the lamellar pattern of spherulites. The top surfaces of the exposed film samples on the bottom micro glass slides were then coated with gold by vacuum-sputtering prior to SEM characterization.

\section{Results and discussion}

POM and optical microscopy (OM) characterization was performed on the $110^{\circ} \mathrm{C}$-crystallized $\mathrm{PEO} /$ PLLA blends of several PEO-rich compositions (PEO $\geqq 50 \mathrm{wt} \%$ ) for further clarifying the correlations between the patterns of the crystalline ring bands and cracks. During the two-stage crystallization (first at crystallization temperature $T_{\mathrm{c}}=110^{\circ} \mathrm{C}$ then cooling to ambient temperature) of the $\mathrm{PEO} /$ PLLA blends, the pre-formed PLLA ring-banded lamellae at $T_{\mathrm{c}}$ serves as nucleating templates for the later-crystallizing PEO species upon cooling to ambient temperature, and then the cracks could be observed after the PEO crystallizing. Figure 1 shows with increasing of the PEO content, the PLLA optical ring bands became less ordered. Under in-situ observation by using POM, long cracks always took place at the impingement of PEO spherulites with the preformed PLLA crystals. At $80 \mathrm{wt} \%$ of PEO in the PEO-rich blend, the PLLA optical ring bands in the spherulites are not distinct or entirely disrupted at all, as shown in the POM graph of Figure 1c. And, the crack pattern was changing from the long radial type to the short irregular type as the content of PEO increase to $80 \mathrm{wt} \%$. There could be found a transition stage of the crack patterns at PEO/PLLA (70/30) blend which had both the radial and the irregular cracks on one sample. Cooling-induced thermal shrinkage due to directional CTE difference alone may not be sufficient in fully accounting for the cracks of these different types.

Figure 2 shows the POM and OM graphs of the water-etched PEO/PLLA blends after the two-stage crystallization. Upon water-etching, it was found that PEO was dominantly and selectively removed from the ridge bands to expose the inner PLLA crystals underneath the ridges. As will be shown in latter results/discussion, PLLA lamellar crystal plates in the ridge region are perpendicular to top surface of

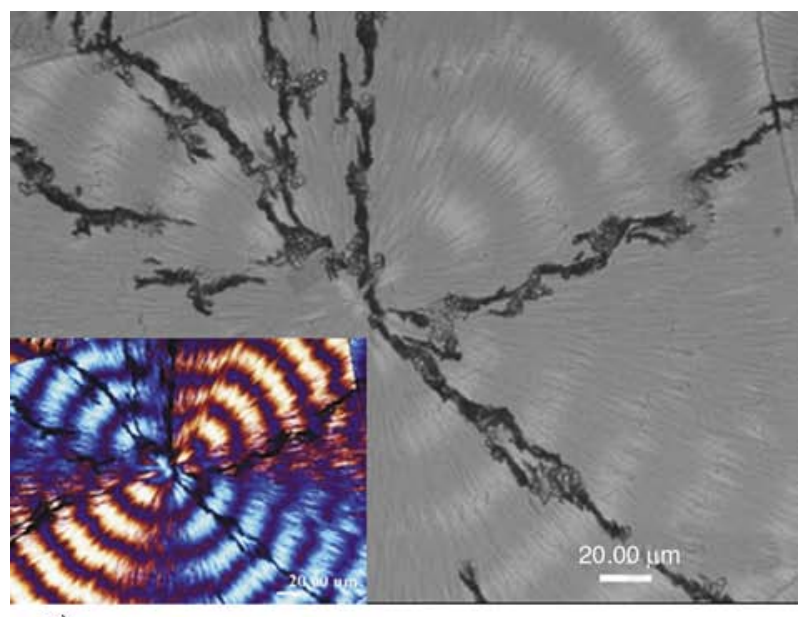

a)

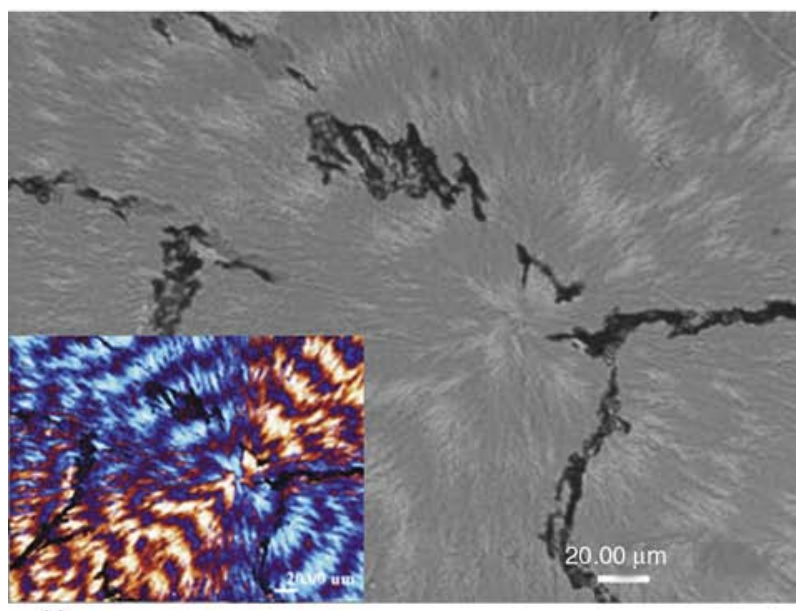

b)

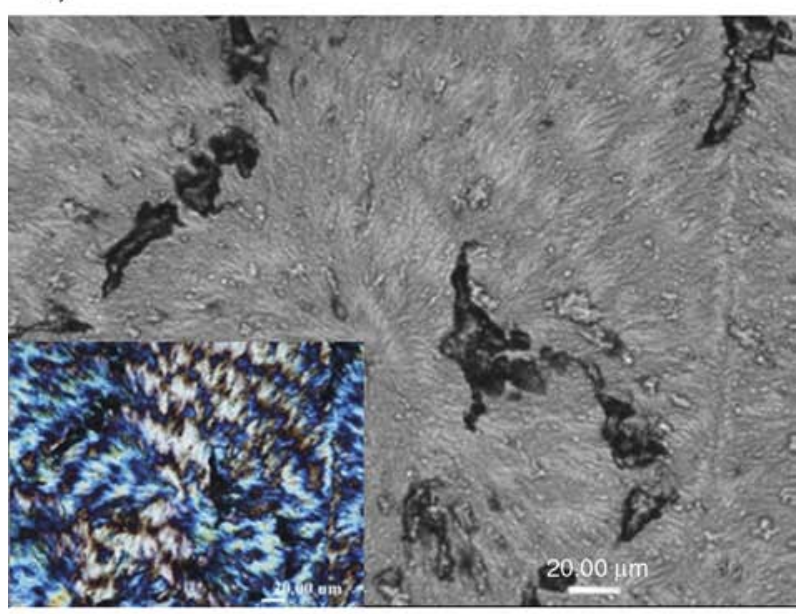

c)

Figure 1. OM graphs of PEO/PLLA blends (unetched) crystallized at $110^{\circ} \mathrm{C}$ then cooled to ambient temperature $\left(25-28^{\circ} \mathrm{C}\right)$ of compositions: (a) $60 / 40$, (b) 70/30, and (c) 80/20 (Insets: POM graphs revealing ring-band patterns)

the samples, and PEO component tends to aggregate between the PLLA lamellae that point upwards. Thus, upon water-etching, the ridge bands were visibly lined with lenticular-shape voids/cracks that were previously occupied by PEO components. The 

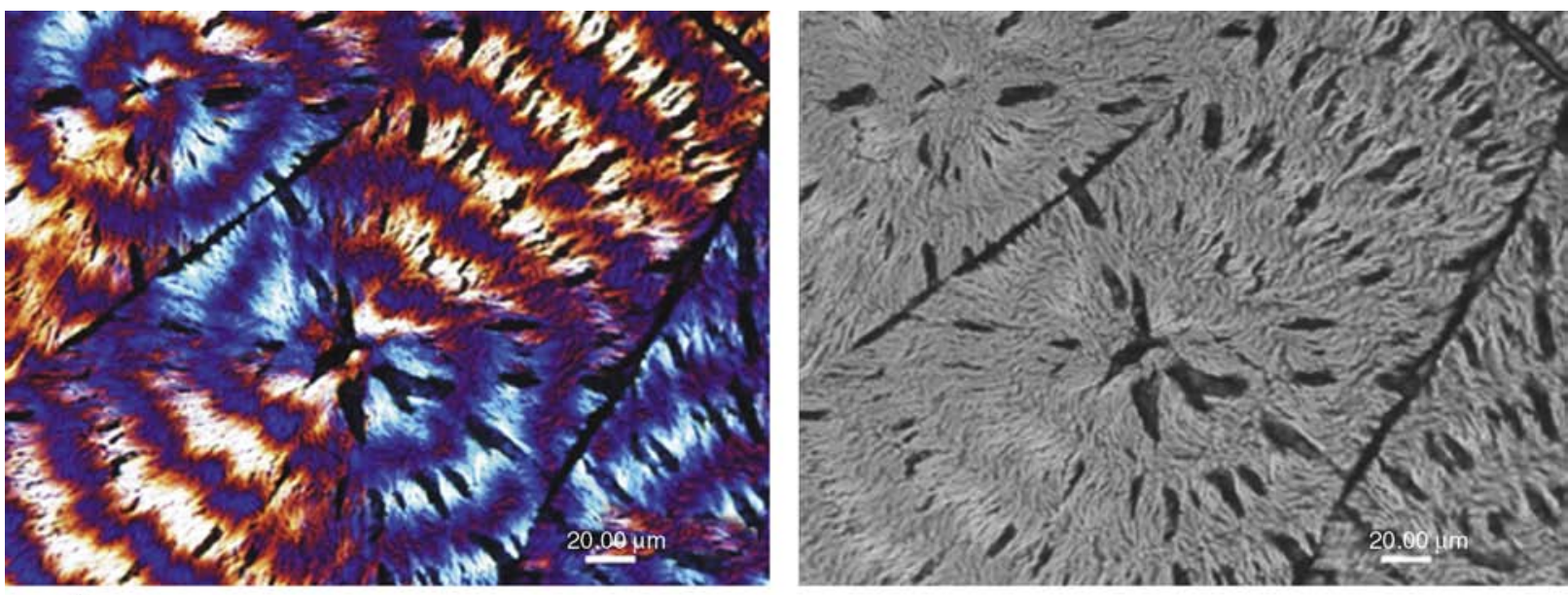

a)
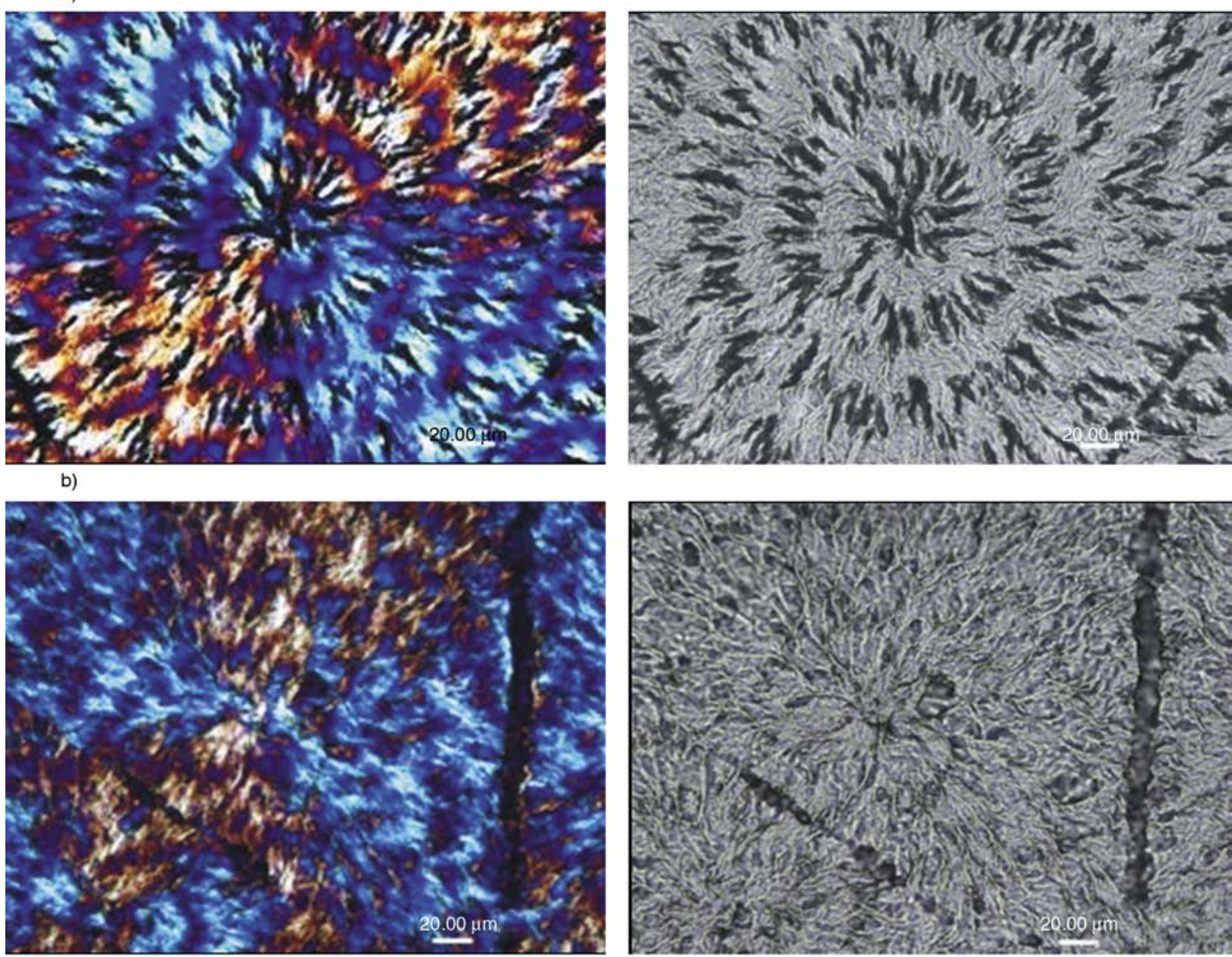

c)

Figure 2. POM (left) and $\mathrm{OM}$ (right) graphs of PEO/PLLA blends (water-etched) crystallized at $T_{\mathrm{c}}=110^{\circ} \mathrm{C}$ then cooled to ambient temperature $\left(25-28^{\circ} \mathrm{C}\right)$ of compositions: (a) 60/40, (b) 70/30, and (c) $80 / 20$

OM graphs for same samples are shown at right side of the POM graphs for comparison of contrast between $\mathrm{POM}$ and $\mathrm{OM}$ imaging interpretation on the etching effect. For Figure $2 \mathrm{a}$ and Figure $2 \mathrm{~b}$, the water-etching affected not only on the bright bands but also dark band; however, the etching took place more severely and circumferentially on the entire dark bands, which was indicated from our previous study [16]. By comparison, the bright band (ridge band) remained relatively unaffected by water etching but the bright band became coarser after etching. For Figure $2 c$, the etching of PEO from the PEO/PLLA (80/20) blend revealed that the PLLA lamellae assumed seaweed patterns, with connected 
voids (initially filled with the etched-off PEO component) bordering by the networking and irregularly twisting micro-lamellae of PLLA.

Figure 3 shows SEM graphs for the fractured surface of two-stage crystallization PEO/PLLA (50/50)

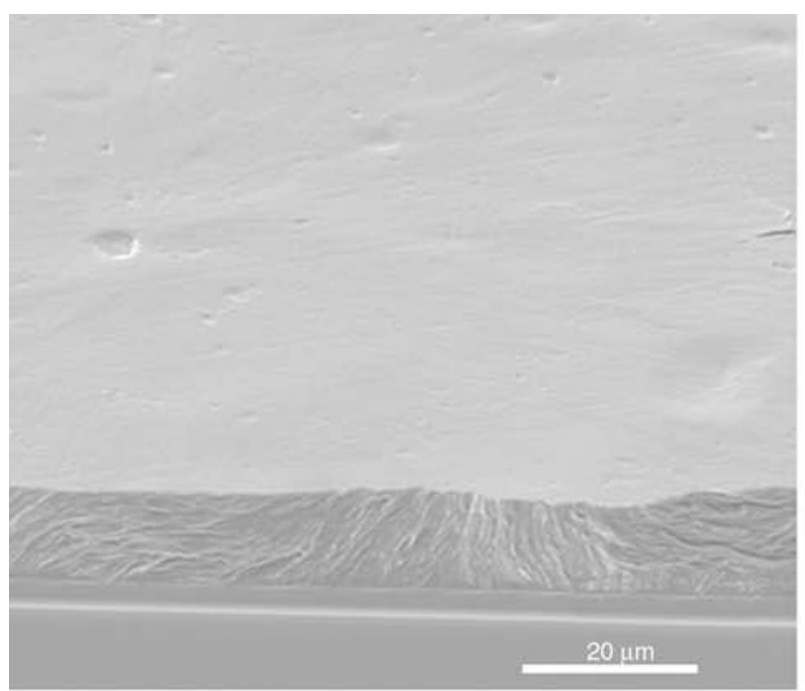

a)

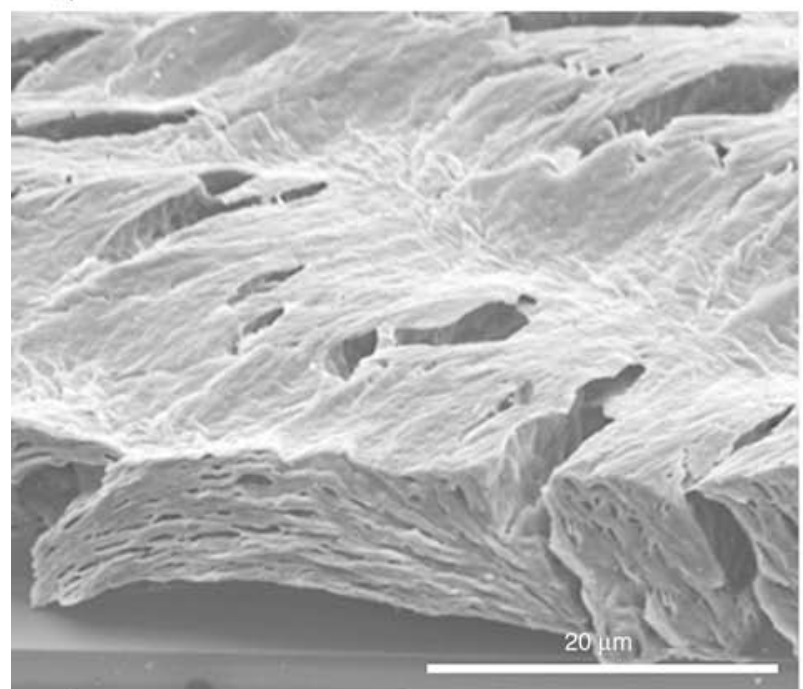

c)

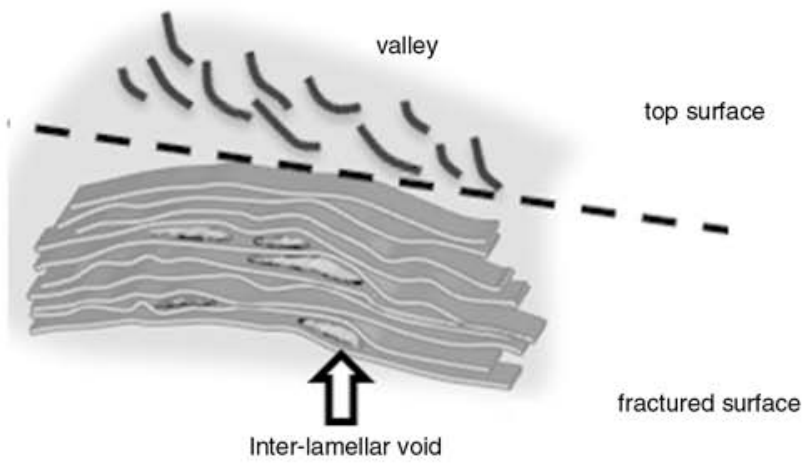

e)

Figure 3. SEM graphs for fractured surface of PEO/PLLA (50/50) blends crystallized at $T_{\mathrm{c}}=110^{\circ} \mathrm{C}$ then cooled to ambient temperature $\left(25-28^{\circ} \mathrm{C}\right)$ of: (a) unetched sample, (b) water etched sample, (c) zoom-in valley 'Region-c', (d) zoom-in ridge 'Region-d'. Schemes of (e) and (f): lamellae assembly and re-orientations of PLLA microlamellae at valley and ridge, respectively. blends of: (a) unetched sample, (b) water-etched sample. As fracture line might cut through the valley or ridge bands, the lamellar patterns underneath the respective valley or ridge could be exposed for analysis. The fractured sample was further water-

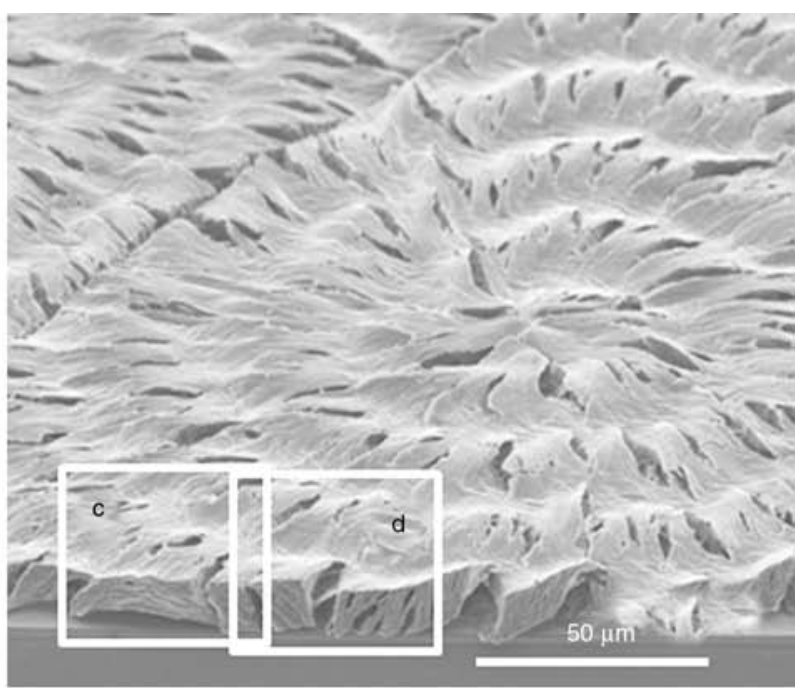

b)

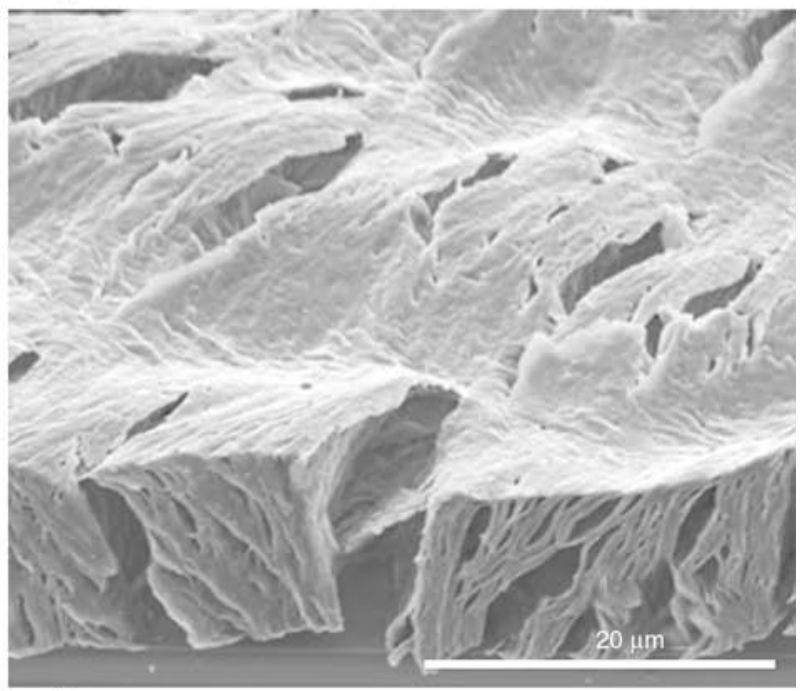

d)

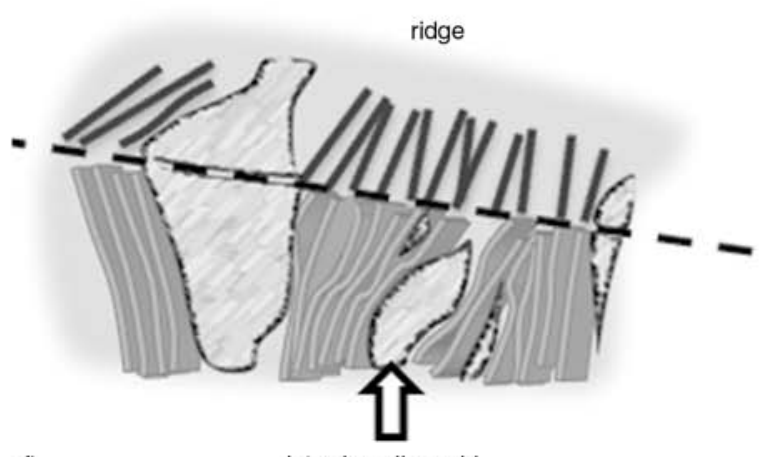

f) 
etched to remove the PEO from the blend and as a result, PLLA lamellar plates were more clearly exposed. The fractured-surface morphology in the SEM graphs display clearly that the lamellar assembly and orientation are oppositely different in the valley and ridge regions. These two regions are zoomed-in and magnified as shown in SEM graphs in Figure 3c (fracture across the valley band) and Figure 3d (fracture across the ridge band), respectively. The lamellar assembly underneath the valley band apparently runs in circumferential direction while the lamellae underneath the ridge band run perpendicular to the film surface. The perpendicular lamellae underneath the ridge band would appear as 'edge-on' when viewed from the top; conversely, the circumferential lamellae underneath the valley band would appear as 'flat-on' when viewed from the top. Details of the micro-lamellar orientation and void patters as exposed in the PEO/PLLA (50/50) were shown in two schemes (Figure $3 e$ and $3 f$ ). The two direction lamellar assembly mention above is at micro-scale, mainly combining from nano-scale PLLA lamellar crystals and amorphous PLLA chains, called as flat-on micro-lamellae and edge-on microlamellae, respectively.

In addition, the fractured and water-etched interiors of PEO/PLLA (50/50) blend also expose interesting correlations between the lamellar plates and crack orientations. Lenticular-shaped voids on the top surface are oriented in the radial direction between the perpendicular edge-on micro-lamellae in the ridge band (bright bands). The schemes, reflecting the actual fractured morphology in SEM graphs shown earlier in Figure 3, show that the voids are not only on the top surface but also on the hidden interior exposed by the fracture surface, as indicated by the arrow marks. On the other hand, with increasing PEO contents in PEO/PLLA blends, the water-etched PEO/PLLA (70/30, 80/20, and 90/10) blends exhibit more irregular twisting PLLA micro-lamellae, resembling seaweeds. The top surface observation results of water-etched PEO/PLLA (70/30, 80/20, and 90/10) blends by using SEM are shown in the Figure 4. As the PEO content increases even higher to 80 or $90 \mathrm{wt} \%$, only the irregularly twisting microlamellae were present, and the micro-lamellae are in less dense assembly. In Figure $4 \mathrm{~b}$ and $4 \mathrm{c}$, some connected voids appear, similar to the OM-revealed result as shown in Figure 2c.

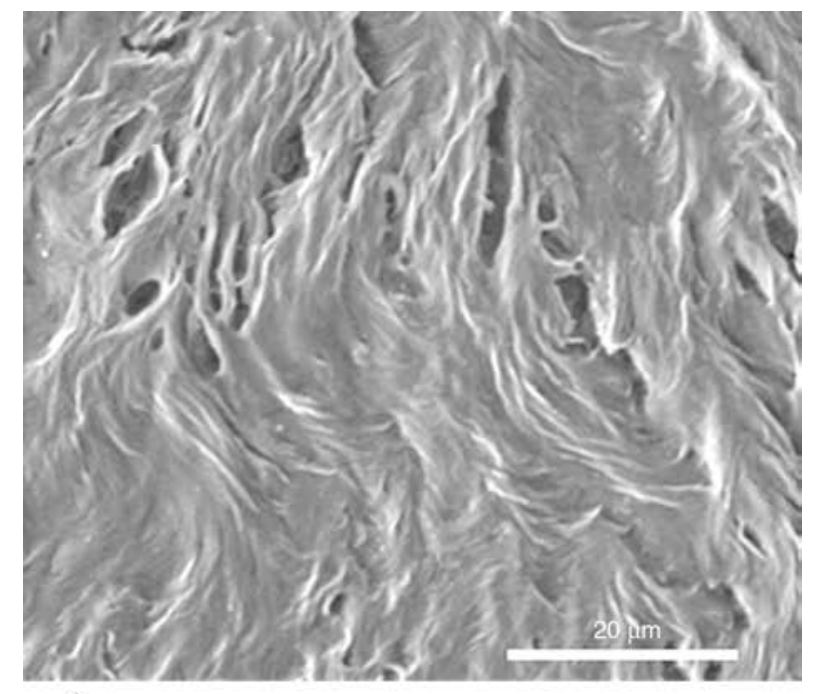

a)

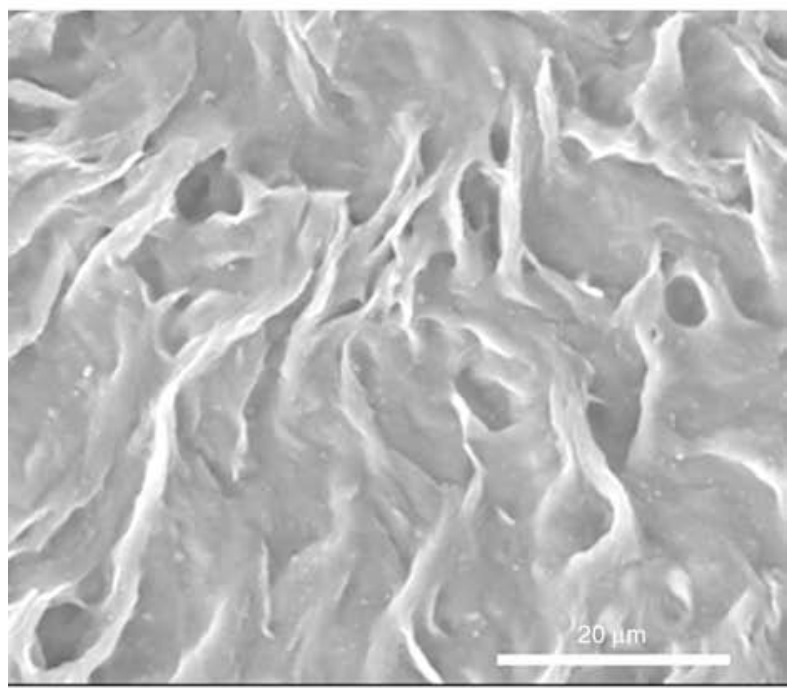

b)

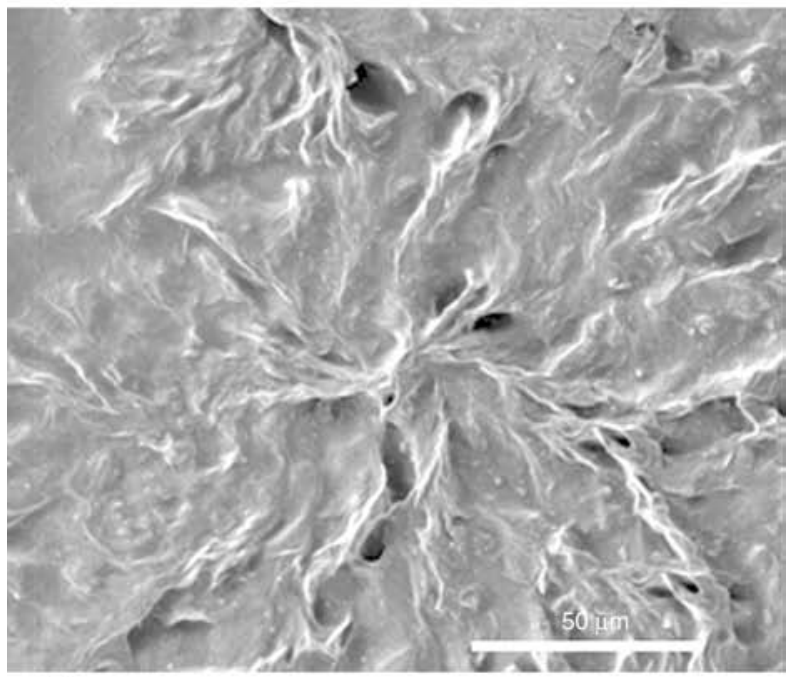

c)

Figure 4. SEM graphs of the water-etched PEO/PLLA blends crystallized at $T_{\mathrm{c}}=110^{\circ} \mathrm{C}$ then cooled to ambient temperature $\left(25-28^{\circ} \mathrm{C}\right)$ of compositions: (a) 70/30, (b) $80 / 20$, and (c) $90 / 10$ 
Figure 5 shows SEM graph and scheme for the fractured surface of the water-etched PEO/PLLA (70/30) blends crystallized at $T_{\mathrm{c}}=110^{\circ} \mathrm{C}$ then cooled to ambient temperature $\left(\sim 25^{\circ} \mathrm{C}\right)$. The upper portion of the SEM graph and scheme are for the top surface, while the lower portion reveals the fracture surface of the water-etched PEO/PLLA (70/30) blend. Fracture line again is seen to run across the interiors of the ridge and valley bands. Similar to the interiors of the PEO/PLLA (50/50) blend, the lamellar plates underneath the surface ridge bands of the PEO/ PLLA (70/30) blend are oriented as perpendicular plates although the lamellar plates are not as regular and orientation is less ordered. The lamellar plates underneath the valley in the PEO/PLLA (70/30) blend are horizontally oriented, but the horizontal orientation is less ordered than that in the 50/50 blend. By comparison, for the PEO/PLLA blend with a higher PEO content at $70 \mathrm{wt} \%$, the lamellar patterns on the top surface are seen to be more irregular and the voids increase in number in comparison to the morphology in the water-etched $\mathrm{PEO} /$ PLLA (50/50) blend. The top surface still exhibits lenticular-shaped voids, but as the packing density of the lamellar crystals are smaller and less regularly positioned, the voids diminish in size.

Overall, the PEO/PLLA 50/50 blend exhibits more ordered lamellar plates underneath the ridge and valley bands; as a result, the unetched 50/50 blend sample exhibits the long radial cracks on the ridge bands when viewed from the top. By contrast, in interior of the PEO/PLLA blends of PEO-rich com-

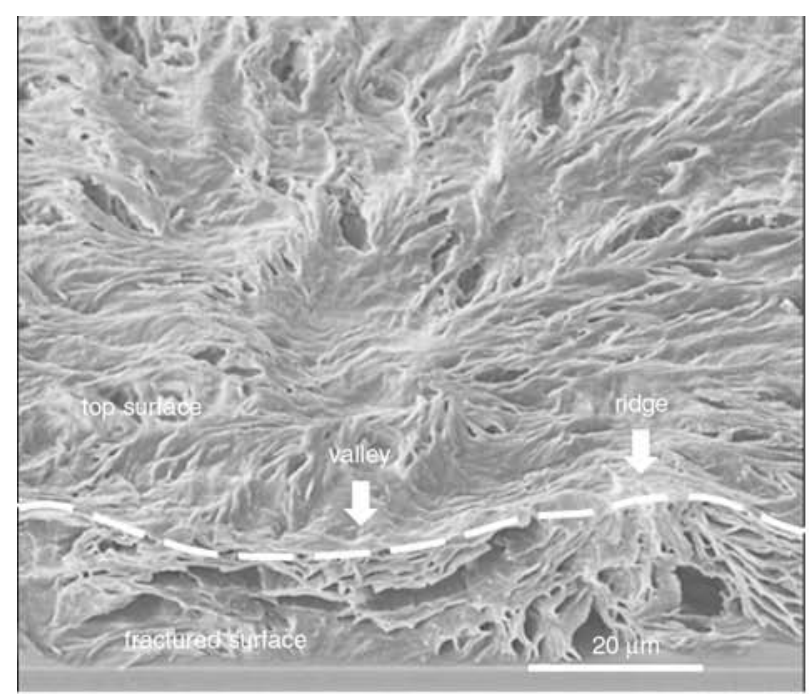

a) positions (PEO content above $70 \mathrm{wt} \%$ ), the lamellar plates are increasingly less ordered, and only irregular cracks of smaller sizes are present. From the $3 \mathrm{D}$ interior dissecting analyses into the interior morphology, it then became easy to comprehend the lamellar assembly and cracks seen in ringed spherulites of the top surface of thin-film PEO/ PLLA samples. Schemes of micro-lamellar orientation and cracks are summarized in Figure 6, which illustrates how micro-lamellar plates interact with crack/ring formation mechanisms in the PEO-rich PEO/PLLA blends of compositions: (a) 50/50, and (b) $80 / 20$ as examples. Ideally, etching of PEO would be more complete if etching was performed at $T_{\mathrm{m}}$ of PEO. Thus, etching by warm water was performed on crystallized blends of several compositions. However, results were not suitable for analysis owing to several reasons. Rings/PLLA lamellae in warm water etched samples were highly disrupted to extents of hardship in subsequent analysis on PLLA morphology. Films would be disintegrated, floated from glass substrate, and bulk samples would be crumbled into irregular particles.

The diagrams on top the schemes are SEM top-surface morphology for PEO/PLLA (50/50 and 80/20) blends. For the PEO/PLLA (50/50) blend, the ridge bands are PLLA lamellae that are oriented perpendicular to the substrate, though with some occasional twist/bending. When the blend was crystallized at $T_{\mathrm{c}}=110^{\circ} \mathrm{C}$, PEO remained molten; but as temperature was cooled to ambient, PEO started to crystallize along the pre-crystallized PLLA crystals.

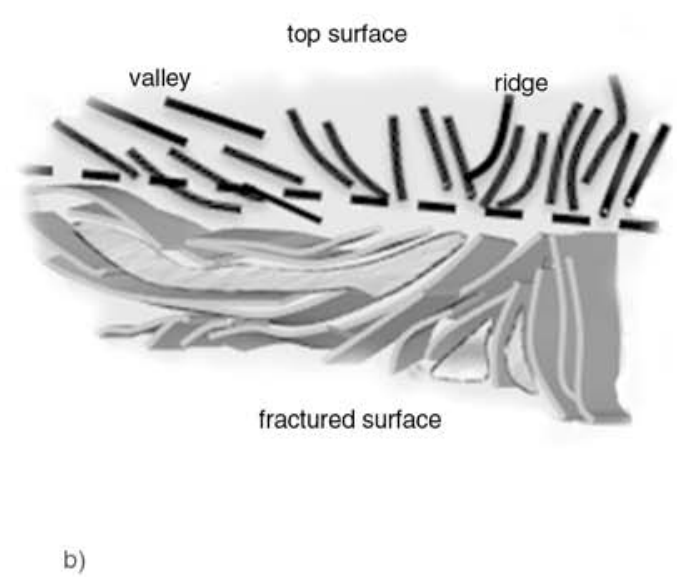

Figure 5. (a) SEM graph and (b) scheme for the fractured surface of the water-etched PEO/PLLA (70/30) blends crystallized at $T_{\mathrm{c}}=110^{\circ} \mathrm{C}$ then cooled to ambient temperature $\left(25-28^{\circ} \mathrm{C}\right)$ 


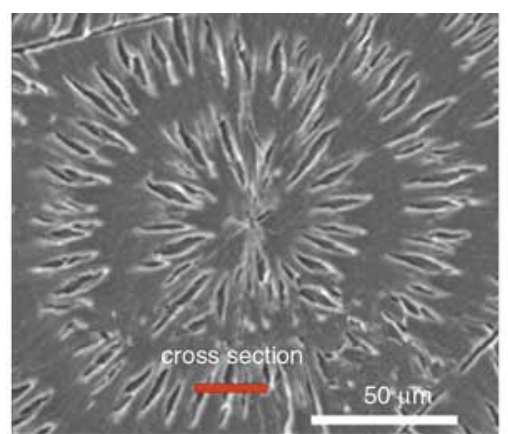

a)
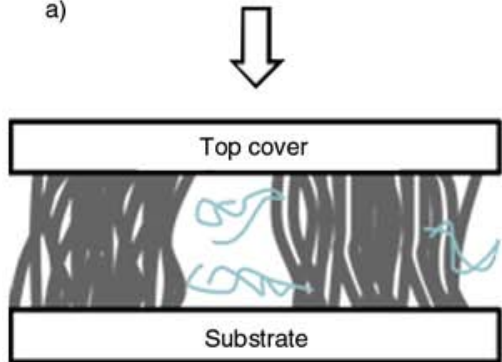

$\sqrt{ }$
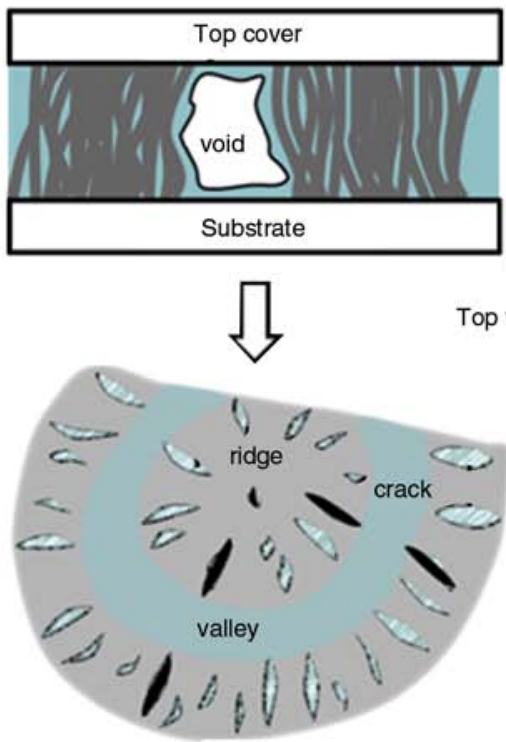

PLLA

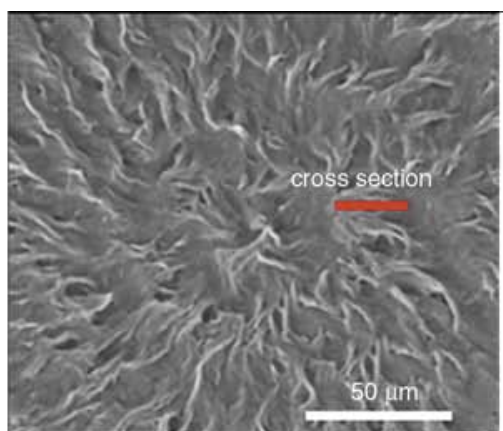

b)
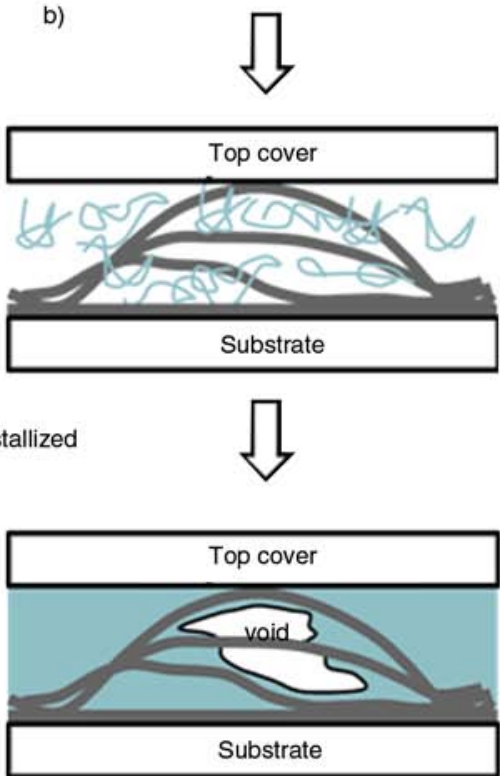

$\sqrt{ }$

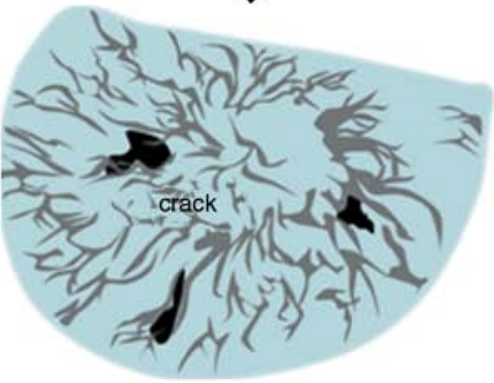

PEO crack

Figure 6. Internal micro-voids/crack formation mechanisms in the PEO/PLLA blends with compositions: (a) 50/50, and (b) $80 / 20$

Thus, PEO molecules were confined in the interlamellar regions of PLLA crystals, substrate and top cover. When PEO crystals met and impinged each other in this limited space, the void appeared from the volume reduction of the PEO crystallization. The void was forced to exist by the density difference between molten and semicrystalline PEO state. At the same time, the crack showed up by using POM observation. With the PEO contents in PEO/ PLLA blends increase to 70 or $80 \mathrm{wt} \%$, the lamellar assembly and crack formation in the PEO-rich blends have similar mechanisms as that in $\mathrm{PEO} /$ PLLA (50/50) blends, but the PLLA lamellar plates decrease in dimensions and orderliness. The PLLA lamellae in the PEO-rich PEO/PLLA blends are increasingly similar to seaweeds with random twists and arrangement, and the lamellae are no longer regularly assembled to perpendicular orientation in ridges and horizontal positions in valleys. Cracks appear to turn as lamellae take turn, and they are no 
longer in the regular radial direction, but take irregular turns with the randomly oriented PLLA lamellar crystals.

\section{Conclusions}

Correlations among internal micro-voids/cracks, ring bands, and interior lamellar assembly in $\mathrm{PEO} /$ PLLA blend were analyzed; and bulk-form and thin-film blend samples with different compositions were probed for interior lamellar assembly extending to outer-surface morphology. By extracting the water-soluble PEO component from the crystallized PEO/PLLA blend of PEO-rich compositions, the PLLA lamellar textures further revealed a complex pattern. The periodical interior micro-lamellar textures in PLLA spherulite as exposing by SEM observation might have further help to construct the structure model for banded spherulites in bulk-form samples. By exposing the interior assembly of thick bulk polymer blend samples that formed either cracks or ring bands on top surface, the interior PLLA crystal assembly, after extracting out water-soluble PEO, was more clearly demonstrated. Such views and aims have been rarely dealt with, if any before in the literature, for revealing the inner PLLA spherulitic structure in 3D (i.e., $x, y$ and $z$-views).

Lamellar-twisting model, though tested and proposed for long time by many researchers, dealt only with semicrystalline polymer samples mainly in thin-film state $(\sim 1-5 \mu \mathrm{m})$. The results in this work have generated alternative, and perhaps richer, views on interior lamellar assembly in thick bulk state that may be responsible for leading to the top-surface crack/ring bands. In $3 \mathrm{D}$ views by cutting across the band ridge and valley, respectively, the lamellar assembly underneath the valley band apparently runs in the circumferential direction while the lamellae underneath the ridge band run perpendicular to the top-surface of samples. Moreover, the internal and exterior voids/cracks in crystallized PLLA always run parallel to the micro-lamellar plates. The radial cracks/voids always coincide well with the ridge band of the alternating ring bands, as underneath the ridge regions, the lamellae plates are oriented perpendicularly to the top surfaces and are easily visible from the top views. Upon cutting across the thickness section of the bulk samples, voids/cracks in the valley regions, on the other hand, are sandwiched between tangential lamellar plates, and thus not visible from the top surface.

\section{Acknowledgements}

This work has been financially supported by basic research grants (NSC-99-2221-E-006-014-MY3) in consecutive years from Taiwan's National Science Council (NSC), for which the authors express their gratitude. The authors especially express their gratitude to Dr. B. Lotz, Institut Charles Sadron, Strasbourg, France, for his careful checking and helpful inputs that have enhanced the depth of the work during progress and manuscript preparation.

\section{References}

[1] Fortunati E., Armentano I., Zhou Q., Iannoni A., Saino E., Visai L., Berglund L. A., Kenny J. M.: Multifunctional bionanocomposite films of poly(lactic acid), cellulose nanocrystals and silver nanoparticles. Carbohydrate Polymers, 87, 1596-1605 (2012).

DOI: $10.1016 /$ j.carbpol.2011.09.066

[2] Yu H-Y., Qin Z-Y., Wang L-F., Zhou Z.: Crystallization behavior and hydrophobic properties of biodegradable ethyl cellulose-g-poly(3-hydroxybutyrate-co-3hydroxyvalerate): The influence of the side-chain length and grafting density. Carbohydrate Polymers, 87, 2447-2454 (2012).

DOI: $10.1016 /$ j.carbpol.2011.11.022

[3] Maillard D., Prud'homme R. E.: Crystallization of ultrathin films of polylactides: From chain chirality to lamella curvature and twisting. Macromolecules, 41, 1705-1712 (2008).

DOI: $10.1021 / \mathrm{ma} 071306 \mathrm{u}$

[4] Fraschini C., Plesu R., Sarasua J. R., Prud'homme R. E.: Cracking in polylactide spherulites. Journal of Polymer Science Part B: Polymer Physics, 43, 3308-3315 (2005).

DOI: $10.1002 /$ polb.20616

[5] He Y., Fan Z., Wei J., Li S.: Morphology and melt crystallization of poly(L-lactide) obtained by ring opening polymerization of L-lactide with zinc catalyst. Polymer Engineering and Science, 46, 1583-1589 (2006). DOI: 10.1002/pen.20617

[6] Nurkhamidah S., Woo E. M.: Effects of crystallinity and molecular weight on crack behavior in crystalline poly(L-lactic acid). Journal of Applied Polymer Science, 122, 1976-1985 (2011).

DOI: $10.1002 /$ app.34021

[7] Nurkhamidah S., Woo E. M.: Correlation of crack patterns and ring bands in spherulites of low molecular weight poly(L-lactic acid). Colloid and Polymer Science, 290, 275-288 (2012).

DOI: $10.1007 / \mathrm{s} 00396-011-2544-3$ 
[8] Martinez-Salazar J., Sanchez-Cuesta M., Barham P. J., Keller A.: Thermal expansion and spherulite cracking in 3-hydroxybutyrate/3-hydroxyvalerate copolymers. Journal of Materials Science Letters, 8, 490-492 (1989).

DOI: $10.1007 / \mathrm{BF} 00720717$

[9] Hobbs J. K., McMaster T. J., Miles M. J., Barham P. J.: Cracking in spherulites of poly(hydroxybutyrate). Polymer, 37, 3241-3246 (1996).

DOI: $10.1016 / 0032-3861(96) 88468-0$

[10] Kuboyama K., Ougizawa T.: Solvent induced cracking and morphology in banded spherulite of poly(trimethylene terephthalate). Polymer Journal, 40, 1005-1009 (2008).

DOI: 10.1295/polymj.PJ2007194

[11] Lee J. H., Kim K. O., Ju Y. M.: Polyethylene oxide additive-entrapped polyvinyl chloride as a new blood bag material. Journal of Biomedical Materials Research, 48, 328-334 (1999).

DOI: 10.1002/(SICI)1097-4636(1999)48:3<328::AIDJBM18>3.0.CO;2-L

[12] Ma G., Fang D., Liu Y., Zhu X., Nie J.: Electrospun sodium alginate/poly(ethylene oxide) core-shell nanofibers scaffolds potential for tissue engineering applications. Carbohydrate Polymers, 87, 737-743 (2012). DOI: $10.1016 /$ j.carbpol.2011.08.055

[13] Nakafuku C., Sakoda M.: Melting and crystallization of poly(L-lactic acid) and poly(ethylene oxide) binary mixture. Polymer Journal, 25, 909-917 (1993).

DOI: $10.1295 /$ polymj.25.909
[14] Nakafuku C.: Effects of molecular weight on the melting and crystallization of poly(L-lactic acid) in a mixture with poly(ethylene oxide). Polymer Journal, 28, 568-575 (1996). DOI: $10.1295 /$ polymj. 28.568

[15] Nijenhuis A. J., Colstee E., Grijpma D. W., Pennings A. J.: High molecular weight poly(L-lactide) and poly (ethylene oxide) blends: Thermal characterization and physical properties. Polymer, 37, 5849-5857 (1996). DOI: $10.1016 / \mathrm{S} 0032-3861(96) 00455-7$

[16] Hsieh Y-T., Nurkhamidah S., Woo E. M.: Lamellar orientation and interlamellar cracks in co-crystallized poly(ethylene oxide)/poly(L-lactic acid) blend. Polymer Journal, 43, 762-769 (2011).

DOI: $10.1038 /$ pj.2011.63

[17] Lustiger A., Lotz B., Duff T. S.: The morphology of the spherulitic surface in polyethylene. Journal of Polymer Science Part B: Polymer Physics, 27, 561-579 (1989).

DOI: $10.1002 /$ polb.1989.090270306

[18] Woo E. M., Wang L-Y., Nurkhamidah S.: Crystal lamellae of mutually perpendicular orientations by dissecting onto interiors of poly(ethylene adipate) spherulites crystallized in bulk form. Macromolecules, 45, 13751383 (2012).

DOI: $10.1021 / \mathrm{ma} 202222 \mathrm{e}$ 